\title{
Students Engaged in Reflection and Practical Problem Solving: Exploring Colour Theory
}

\author{
Tiiu Poldma, Lora Di Fabio, and Zakia Hammouni
}

\begin{abstract}
This paper explores how students connect meaningfully with theory through the aesthetic experiences of problem solving together in the context of a workshop. It can be challenging for students studying design in university programs to understand how theory is relevant, when applied in practical design studio activities. In the colour workshop presented, students participate in brainstorming exercises to create proposals. Theory is made meaningful through learning activities, including a creative brainstorming session animated by both teachers and industry guests. The experience described was enthusiastically received, with the academia-industry collaboration providing a valuable platform for knowledge exchange both among students and teachers.
\end{abstract}

\section{Background}

Reflection and practical problem solving are foundations for learning in the visual arts disciplines. In visual arts programs such as design and architecture, learning consists of a particular combination of courses that cover both theory and practical design studio courses. We present a colour workshop exercise within a theory class, wherein students learn theory as abstracted concepts and then apply the theories learned into hands-on design studio problem solving during a workshop on colour. Too often, while students want to learn, in numerous university design programs, theory is not always easy to grasp for many students. Theory is taught to impart possibilities and contexts for informed decisions in design thinking and doing for students who study in disciplines such as architecture, design, and interior design. These disciplines require an understanding of theory that often introduces ideas that are completely foreign to students. They must be able to then understand how that theory is applied in decision making about the design of various types of physical built environments, both exterior and interior. A theory-based application into practice is vital for students to understand as lived experience in one form or another as they are learning. This is a particular form of "thinking" and "doing" wherein theory is understood in the real-time experiences through classroom exercises that are informed by problem- or project-based learning (Vaikla Poldma, 2003). Once theory is understood, students apply concepts into situated problems. When problem solving, they are engaging in thinking differently about a subject and are often imagining "something that does not-yet-exist" (Nelson \& Stolterman, 2012, p. 35). This type of learning is supported by a problem-based approach in which theoretical concepts are applied into projects or problems. This then sets the stage for understanding through experience-based activities in the classroom. Creating a learning environment that empowers students with decision-making skills based on grounding the theory, is part of the "thinking and doing" that occurs. In the course discussed 
in this paper, we are teachers who engage students with theories and ideas about colour, its contexts, and applications, and then explored by students brainstorming about colour use in the environment. Subsequent choices that the students make are informed by historic, theoretical, and contextual aspects of the problem at hand.

This workshop was in the context of a second-year theory course on light and colour in a Bachelor-level interior design program at Université de Montréal in Montreal, Canada. The activity described here took place in February 2020. The two teachers (Zakia and Tiiu) worked together with an expert in colour (Lora) to create the Chromazone workshop on colour. Subsequently, students were selected to participate in the Color Marketing Group's two-week workshop in Montreal on the same theme with Tiiu and Zakia.

In the class, during the first few weeks before the workshop, students learned basic theories such as the physics of light and colour, vision, physical properties of colour (theories), principles and theories, and diverse contexts such as cultural, psychological, and historic uses of colour. They learned about the more dynamic ways that colour and light interact and are used in the design of diverse products and environments, in terms of ambiance and atmosphere when designing interiors and as theories are applied. The goals of the workshop were to put theories about colour, learned by students in earlier sessions, into practice. Students expressed their ideas, as well as their reactions to the project, to the authors both during and after exercises. Lora, Zakia, and Tiiu explore what happened in terms of students and their experiences, and what perspectives are provided about the workshop that bring together theory, contexts, and brainstorming results in exciting ways.

\section{What Is the Color Marketing Group and the Color Forecasting Workshop Activity in the Classroom?}

The Color Marketing Group (CMG) is a nonprofit international colour forecasting organization based near Washington, D.C., that conducts workshops with various colour professionals and schools around the world. CMG is a forecaster of trends, and colours are selected yearly worldwide, based on local workshops such as the exercise that we conducted in the classroom.

Tiiu and Zakia, the teachers in the class, were approached by the Color Marketing Group and Chromazone workshop organizer, Lora, to facilitate such a workshop in the class of 50 students. Together, we developed the workshop ideas based on the previous workshops that Lora had conducted. Zakia and Tiiu decided to conduct the workshop in class consisting of two parts:

1) A "show-and-tell" presentation of the Color Marketing Group and how colours are forecast every year globally, with homework preparation that same week (week 1); and 2) A one-day workshop with brainstorming and a goal of solving a specific colour problem in teams of two students (week 2). This was followed by the production of the final concept boards for the submission the following week. We asked the students to solve a particular design problem and to innovate with new ideas, using the colour theory learned in the classroom, and to add their personal and contextual knowledge in framing their responses. 
They were then to visually represent the ideas that they conceived in the form of "concept boards" with their colour choices, integrated within the template provided by CMG.

The actual workshop activity unfolded over a two-week period. During the first week in the "show and tell" phase, the Color Marketing Group (CMG) representatives Lora and Natalie presented the Colour Forecast approach and what was expected in terms of the colour choices and how these would be made. The project description was reviewed with students and the preparatory work was explained in advance, so they could form into their groups and do some simple preparatory research to prepare for the following week, when the workshop brainstorming session would occur. Second, at this first presentation session, the guidelines and PowerPoint templates (in English and French) were provided for the students to follow. This provided a springboard for idea development prior to the brainstorming session, guidelines about images to be chosen, so that each group would have a uniform format to follow.

The learning exercise included understanding the goals of the CMG, understanding theories about colours, how we psychologically and contextually choose colours in our environment and what emotions are triggered with certain choices of colours and images to create a feeling, an ambiance, or a response to a particular need.

After the first week of the activity, and as part of their research homework, we also asked students to bring in inspirational images and photos based on the information that they were given by CMG and the teachers. They were also offered multiple free online sites to explore and to help them to select the colours and images that they might use. However, they did not know the problem until they arrived for the brainstorming session in the second class one week later. At home, students were also encouraged to explore ideas by thinking about trends and forecasts of colours as well as emergent issues in society. They were encouraged to research potential ideas, find images that reflected their ideas about colour, and consider what they envisioned for the forecasting of colours in 2022.

During the second week workshop activity in the classroom, students were given the assignment and were grouped into small teams of two people. They were introduced to the activity with an inspirational video to trigger their thinking at the outset, about future trends and what the CMG has already accomplished in workshops in past years. From there, they worked in their groups freely, and created concepts based on a variety of visual brainstorming techniques, creating collages and other visual compositions with colour chips and visual images.

From that second brainstorming session, students produced final solutions in the PowerPoint template, complete with images and stories that were handed in the following week.

\section{Theories Behind the Activities: The Pedagogical Approach}

As students advance in school, it is valuable to learn theory and then understand its value in practice, and, in design schools, practice a hands-on aesthetic experience. However, in most design baccalaureate programs, theories are often taught separately from the designing. One of the goals of theory at the baccalaureate level is to impart knowledge about a particular subject. Then in the design studio, theory 
and practice come together to engage students in the "thinking" and "doing" of learning concepts that are conceived for practical solutions to practical or theoretical problems.

Theory can be dense for students to understand. In particular, the students in design classes generally do not come from physics backgrounds usually needed in understanding vision and colour. Subsequently, in the situation of the colour and light course described, the colour and light theories taught in the course are difficult to absorb and students can be relatively unmotivated to use them. Meaningful learning happens when the ideas can be explored and developed to their fullest potential in the situation of a hands-on problem in the theory class.

Students often learn theories that are the basis for initial knowledge. Then they apply theories into problem-solving exercises as a form of "thinking and doing"—pedagogical approaches to engaging students to creation and innovation. This idea of "thinking and doing" is predicated on a constructivist approach situated in collaborative learning. That is, theory is understood and constructed together in discussion in the classroom. Then the theory is put into practice in the exploration of concepts applied into problem solving. The problem design and understanding provide a place to then reflect back into theory (Vaikla-Poldma, 2003), as a reflective approach to learning. These ideas are informed by a constructivist view, in that students learn theory and then construct the ideas through problem solving in particular situations that they experience in classroom learning and that are based on the eventual professional experiences that they will have. (Pena \& Parshall, 2012, p. 58). They then reflect on choices and the impact these will have on their professional practices as they acquire these new skills (Schön, 1983).

\section{Learning as Experiential}

The premise in the classroom is that theoretical ideas are learned and then understood through the lived experiences in both discussion and exercises. As John Dewey notes, it is in the aesthetic lived experience itself that one understands the concepts. According to Dewey, to have an idea and get an idea of reality is to experiment with this idea, to confront it with a real-life situation and then verify (or disprove) the idea (Dewey, 1934, in Ross, 1992; Dewey, 2005). Furthermore, Dewey suggests that it is through aesthetic experience that understanding of the subject or object emerges, be this a work of art or a design ideas/concept. With this perspective in mind, the students tested several possibilities and aesthetic solutions through combinations of colours, lights, and finishes to decide on their design solution to the colour exercise. This aesthetic solution then led to an understanding for each student individually, and as expressed by the student in the form of a visual representation. Their aesthetically motivated ideas generated solutions and concepts also provided understanding for them personally. In the case of this workshop, the aesthetic choice concerned light and colour choices that students made, and that evoked a particular aesthetic experience (Dewey 1934/1992); and this is what students create: they produced concepts to evoke reactions and that integrated image, colour, and text to elicit understanding of what the colour they chose might elicit as aesthetic responses for those for whom the colours will be chosen. 


\section{Reflective Learning as Understanding Reflecting in Practice}

In the Baccalaureate Program (in interior design where these activities occur), theory is provided for its potential application in the resolution of spatial design problems within professional practice. In the world of architecture and design, students learn reflective practice skills in decision making. Students then make choices to put ideas into the reality of the built interior environment or building that is conceived. When a designer is in the field, their practice demands these types of "thinking and doing" skills. Schon suggests that reflective thinking is a process that is used by students to make decisions about their choices and the design solutions that are proposed. This process is complex, considering the different decisions that go into making a choice (Schön, 1992). In the case of this workshop, the complexity of the situation that demanded reflection, included making decisions about which colours to choose in creating a colour forecast, and arguing for, or building a story, around these choices. In our workshop, the choices made then became the solution to a colour proposition.

\section{The Problem-Based Approach}

The exercise was part of a larger course content that is predicated on a "problem-based" approach (Cinnéide \& Tynan, 2004). In this approach, it is the problem that situates the student inquiry and subsequent choices that they make, guided by a teacher in a conversational and collaborative approach that seeks to support students' learning through discovery and inquiry, wherein reflection on the issues creates the conditions for ideas to emerge and a solution or two proposed. In the workshop, there was an added dimension of students negotiating their choices with one another, as well as answering the problem that was presented to them, and to do so in an innovative way.

Understanding the problem and reflecting on the potential ideas for a solution are thus manifested in the workshop, between the different participants, the tutor facilitators, and the student. All participants brainstorm together, and students focus their discussions about the choice of colours and the themes that they want to develop. As Schön points out, the language used by the designer/student to describe and appreciate the consequences of their choices are made by choices of representative images accompanying their choice of colours and the explanation that accompanies this choice. These choices are based on a multitude of ideas, influenced by, and not limited to, nature, culture, historic nuance, or ambiance as subjective descriptors to help situate the concept that is developed (Schön, 1992).

\section{Why a Colour Workshop? Reflections on the Workshop Process and Solutions}

One of the issues with learning about light and colour, is that the ways we use these theories in the practice of designing is somewhat difficult to show, and even more difficult for students to understand and assimilate the theoretical concepts for use in design studio solution creation. We create ambiances using both colour and light. Colour, however, only becomes apparent when invisible light waves react and reflect of materials and surfaces and our eyes then receive this visual information, which our brains interpret as an object such as a red apple, or an interior that is warm and cozy. For these ideas to take 
root with students, exercises about light, colour, and their properties are a first means to understand theories and learn how to put them into practice.

During the colour workshop, students were deliberately placed into small groups of two to learn collaboratively together. This stimulates both reflective thinking and the development of ideas using collaborative strategies. Once in the classroom in the second week, the workshop brainstorming session happened. The students sat together in their preassigned groups. They had been introduced to an inspirational video on this topic, to get inspired and prepare to make their own choice of colours and to put together a story corresponding to those colours. They then had the rest of the time of the class to develop their two concepts for forecasting.

In terms of the classroom environment, Zakia and Tiiu created a collaborative environment for a brainstorming session that happened over a three-hour period, with breaks. The seating was rearranged in an informal manner, encouraging creative work, and snacks were provided, creating an atmosphere of comfort for all to relax and enjoy the exercise, working collaboratively with one another, in between groups and with the professors. Colour samples and catalogs were provided with Internet links to search for inspirational images for unrestricted use.

As the teachers, we became facilitators, answering questions and generally guiding students as needed. We also participated in the exercise and created two concepts as well. We organized ourselves within the class and proceeded to work alongside the students, creating two concepts for the forecasting as required by the project parameters.

Students were animated and engaged in exploring both their ideas and diverse contexts. As we see in Figure 1, the contexts presented are supported by both a sense of cultural contexts and an aesthetic linking of philosophical ideas.

Figure 1 shows one example of one student's project result:
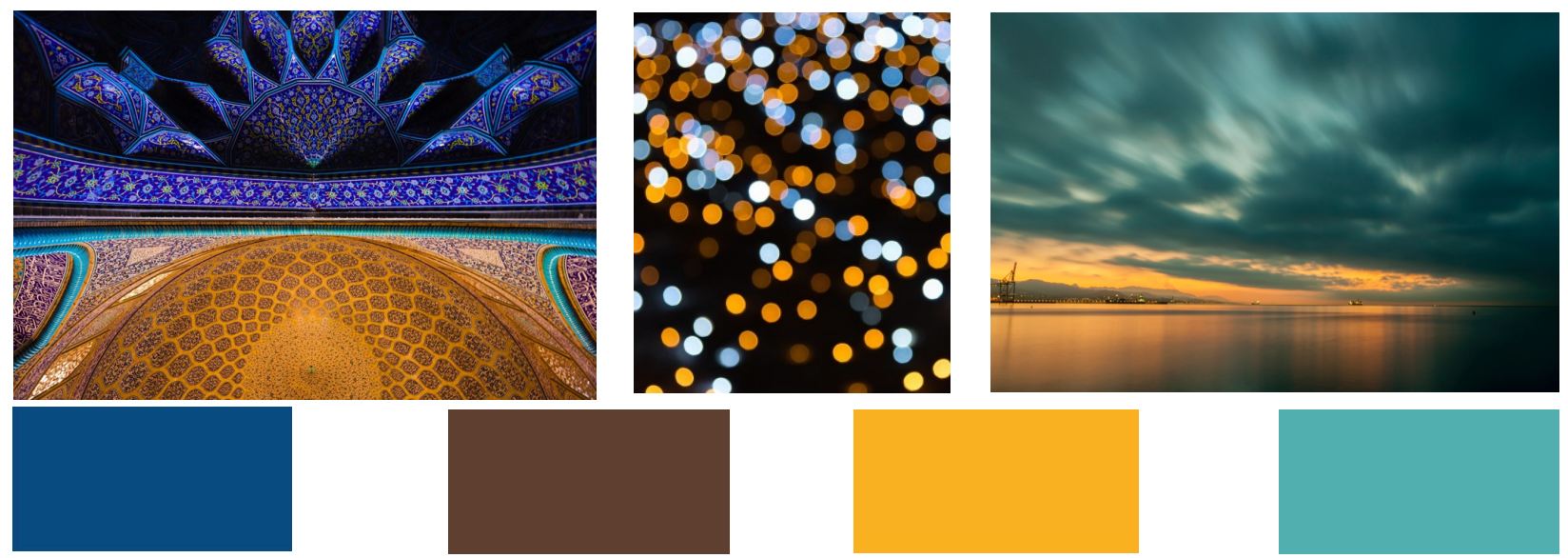

Fig. 1: Kafia's concept: "Path to the unknown"; Kafia Kaafarani, 2020. (Image credits: https://unsplash.com/photos/7rCuljbwBR0; https://unsplash.com/photos/yaiy4mCbzw0; https://unsplash.com/photos/7cjDM0QBssc 
Here in Figure 2, we see a second example of another student exploring in the context of rediscovery and personal development, in light of a changing and uncertain world:
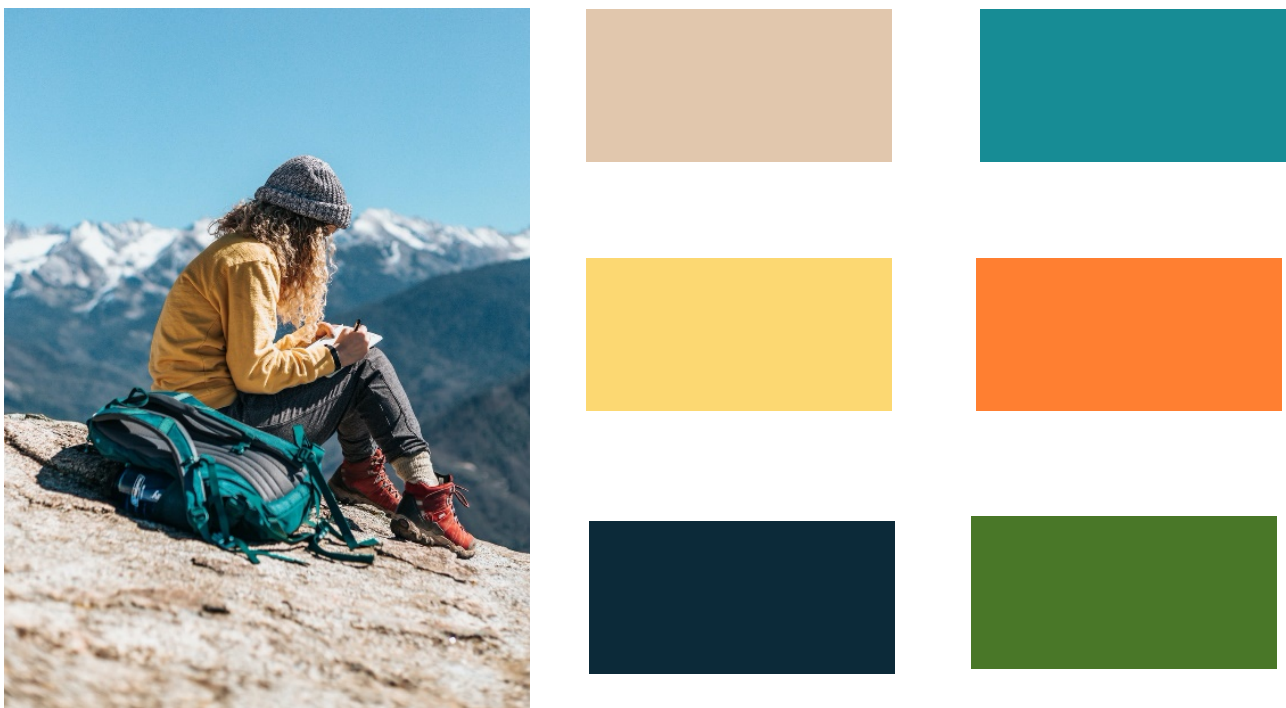

Fig. 2: Béatrice's concept: "Rediscovery"; Béatrice Martin-Blanchet, 2020. (Image credit: Nix, T. https://unsplash.com/photos/qmotCAvPBM)

During the workshop, each group narrowed down their initial ideas into two proposals (one by each student), pondering new implications that are considered and that make their choices unique. They then finalized their solution by proceeding with flexibility towards this solution with which they have started the initial dialogue (image, story, choice of colours).

\section{Discussion, Reflections, and Post-Workshop Activities}

The exercise was enthusiastically received by most students. The environment was very friendly, and the students were animated during the activity. Both professors were impressed with the overall results, given the short timeframe of the activity. Every group provided both interesting perspectives and innovative choices of colours based on their research and the design contexts that they established through the themes that they chose. Students were able to understand the value of the colour theory and the meanings attached to colour choices when these are made. This was a natural outgrowth of the exercise, as they were obligated to attach stories to the colour choices made. In Figure 1, for example, the story is told as follows:

As humans, we ask ourselves questions about life, death and the unknown, which is in the culture of humanity. Indeed, we seek to find answers to the great questions of life. There is a human struggle to find information and answers to be able to progress as a society.

"Path to the Unknown" represents what seems dark, mysterious, and unknown to humans. It symbolizes the cosmos as well as infinity and beyond. (Loose translation)

The story attached to the concept in Figure 2 is framed differently: 
Recently, the nature of travel seems to have changed. More and more, travellers are moving away from the all-inclusive holiday package and moving towards a more adventurous form of travel. This search for authenticity, natural spaces, and meaningful life experiences are at the heart of our travels today. This phenomenon is probably explained by the evolution of the minimalist current. More than a stream of aesthetics, the latter prompted people to reevaluate their priorities and favour experiences over possessions. The phenomenon is also linked to a renewed interest in natural spaces and responsible tourism due to the worrying environmental situation of our Earth. In response to the current containment situation, "Rediscovery" represents the desire for freedom and exploration that is felt around the globe. (Loose translation)

The colour choices are reflected back to the context, which again are reflected back on a theme or other context, such as historic or cultural.

Students were also quite engaged. During informal discussions after the workshop had ended, they expressed their enthusiasm about the workshop exercise. A few positive comments were also made about the surprise they felt when their teachers participated in the exercise as well.

\section{Workshop Follow-Up and Chromazone 2022+}

Following the workshop, we (as the teachers) evaluated the projects as an academic exercise. Then, following the end of the course, a separate jury was created to select a few of the best projects for consideration in the Color Marketing Group's workshop Chromazone 2022+. Similar workshops were held worldwide in 2020. Students who were selected were invited to participate in one of 11 North America-focused workshop exercises, which was conducted online, due to the onset of the COVID-19 pandemic, just after the in-class workshop had taken place in February 2020.

This worldwide workshop was the second phase of the process and was conducted around the world, with one workshop hosted in Montreal in the Summer of 2020. Of the 28 groups that had submitted work, four teams were selected as finalists and two teams participated in the Montreal workshop conducted by the Color Marketing Group, Chromazone 2022+.

The students also enjoyed the experience immensely and felt that the workshop was an enriching experience (personal subsequent communications with the two professors. We were also invited to participate in the workshop).

\section{Lessons Learned From Both Students and Collaborators}

This workshop was a positive, dynamic experience for the students, both in the classroom and for the students who also participated in the Chromazone 2022+ Montreal workshop. The theories learned in this course on light colour ambience, historical psychological and cultural contexts of colour use, and how to consider the different aspects and psychological effects of a colour, were foundational to the application later on in the workshop problem-solving process. This workshop also allowed the students to put into practice their skills and knowledge acquired through active participation in the real-world situation of the colour workshop. Such activities enhance students' abilities to understand how their 
concept development for a particular problem was enhanced by theory and by their application of their ideas into practice.

This was a dynamic and positive collaboration with industry as well. As Lora notes:

As a student once myself, I clearly remember the guest speakers from industry who came to speak to the students. For years I've made a point of returning the favour and have lectured on colour as it is applied in a work/manufacturing setting. What strikes me every time is the curiosity and interesting questions one gets from students. The Q\&A session with the students in this workshop was no exception. The workshop offered valuable results, which is not surprising given the interest and thoughtfulness it received from both faculty and students alike.

Students benefitted from industry presentations and participation in their theory course to encourage thinking. The presentations also helped to situate for the students how the exercise is of value, in terms of how this emulates the potential for the choices that they will ultimately make in the real world. Students could understand, through the lived experiences and exercises they completed, the relevance of theory to practice directly through the workshop experience. Quite often, colour is not deemed a valuable component of the design project, and this exercise elevated thinking about colour and its impact in new and innovative ways. This thinking was then manifested in the solutions that the students proposed. Industry collaborators were impressed with the students' work and results.

On a final note, Lora mentions that,

The quality of the work was at a high level. Moreover, the work entered for final judging was chosen to be part of the final 2022+ North America Color Forecast. No small feat, given the amount of entries submitted from across North America.

\section{Conclusion}

Through the activities of this workshop, students learned how to put theory into practice, and to collaborate in teams to develop solutions for a problem, paralleling the actual design studio experience in the field. There was engagement between students, collaborators, and teachers, creating an enriching experience, and a meaningful way for students to adapt theory into practices through the exercise that reflected activities in the real world. This collaboration provides a valuable platform for knowledge exchange, comparison, and collaboration between academic institution and industrial institution.

Through the aesthetic experiences they encountered, students were empowered to discover new and different light-colour mood solutions, and new ways to promote their ideas. Our conviction is that future workshops can be facilitated using this approach. Overall, the activities of this workshop contributed to changing perceptions about the light-colour aspects of the environment for students. Thinking and doing thus become a way to express and discover aesthetic experiences, that allows for problem solving that is relevant for professional activities and meaningful to students. Future possibilities include incorporating this type of workshop into theory courses, where there is a need to help students understand theory and its relevance to their learning. 


\section{Acknowledgments}

Many thanks to Béatrice Martin-Blanchet and Kafia Kaafarani for their contribution of the works shown in this paper. Many thanks to all the students who participated in this workshop at Université de Montréal in the winter of 2020, and to Lora DiFabio, whose guidance with Natalie Pope, enriched the student experiences.

\section{References}

Cinnéide, M. Ó., \& Tynan, R. (2004, 28 June). A problem-based approach to teaching design patterns. ITiCSE-WGR '04 (p. 80-82). https//doi:10.1145/1044550.1041663

Dewey, J. (1934). Art as experience. In S. D. Ross (Ed.), Art and its significance: An anthology of aesthetic theory (3rd ed., pp. 203-220). State University of New York Press.

Dewey, J. (2005). Art as experience. Perigee.

Nelson, H. G., \& Stolterman, E. (2012). The design way: intentional change in an unpredictable world (2nd ed.). The MIT Press.

Pena, W. M., \& Parshall, S. A. (2012). Problem seeking: An architectural programming primer (5th ed.). Wiley.

Schön, D. A. (1983). The reflective practitioner: How professionals think in action. Basic Books.

Schön, D. A. (1992). Designing as reflective conversation with the materials of a design situation. Research in Engineering Design, 3(3), 131-147. https//doi:10.1007/BF01580516

Vaikla Poldma, T. (2003). An investigation of learning and teaching processes in an interior design class: An interpretive and contextual inquiry [unpublished PhD thesis]. McGill University. 


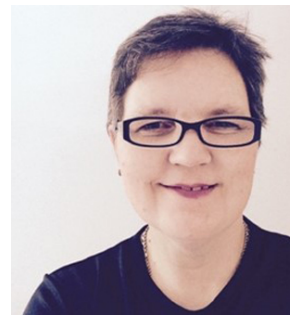

Tiiu Poldma is a Full Professor at École de Design, Faculté de l'aménagement, Université de Montréal. She holds a BA Honours (Ryerson University, 1982), MA Honours (McGill University, 1999) and PhD Doctorem Philosophae (McGill University, 2003). Research interests include adapting interior environments using participatory action research-based approaches, with the goal to empower people as agents of change through design actions. Teaching activities promote an understanding of universal and humanitarian issues in the global environment and designing humanistic interiors. In 2015, she received the Fellow of the Design Research Society in recognition for her work in design research.

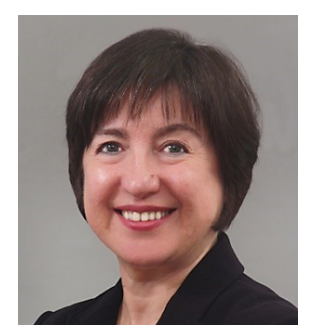

Lora Di Fabio is Design \& Development Manager at American Biltrite where she leads the design development of flooring products and marketing materials. After receiving her BFA (Honours in Graphic Design) from Concordia University, Lora has worked at Industrial Design firms and corporations where she specialized in colour and graphic applications on consumer products. She has often lectured on Colour in Manufacturing at the University of Montreal School of Design. Today, Lora sits on the Board of Directors of the Color Marketing Group and serves on the CMG Color Forecasting Committee where she helps steer the North American colour forecasts.

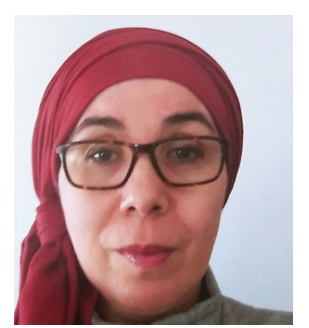

Zakia Hammouni is a $\mathrm{PhD}$ candidate at the Faculty of Environmental Design, Université de Montréal (Canada). She is a CRIR student member - Centre for Interdisciplinary Rehabilitation Research of Greater Montreal and assistant educator in the Baccalaureate program in Interior Design (Université de Montréal). She has a Masters' degree in architecture and environment, a Masters' degree in Design and Health, and a First cycle doctorate in medicine. She is a research assistant in the research lab FoCoLUM/GRID (Université de Montréal). Her research focus includes person-centered-design, universal design, well-being, and healthcare design. 